\title{
The Feeling of Personal Ownership of One's Mental States: A Conceptual Argument and Empirical Evidence for an Essential, but Underappreciated, Mechanism of Mind
}

\author{
Stan B. Klein \\ University of California, Santa Barbara
}

\begin{abstract}
I argue that the feeling that one is the owner of his or her mental states is not an intrinsic property of those states. Rather, it consists in a contingent relation between consciousness and its intentional objects. As such, there are (a variety of) circumstances, varying in their interpretive clarity, in which this relation can come undone. When this happens, the content of consciousness still is apprehended, but the feeling that the content "belongs to me" no longer is secured. I discuss the implications of a mechanism enabling personal ownership for understanding a variety of clinical syndromes as well normal mental function.
\end{abstract}

Keywords: consciousness, experiential reality, mental states, mind, personal ownership

"If you want to know what something might be good for, examine the situation where it is no longer present" (Weiskrantz, 1997, p. 6)

The ability to read the above quote, though deceptively simple in practice, is a quite remarkable achievement. A cascade of subexperiential processes must, on serious reflection, come into play-including, but not limited to, attention to the printed symbols, mechanisms that convert the attended objects to meaningful content, fitting this content to the context in which it is encountered, and so forth.

After extensive processing, the content of this subexperiential analysis will (under normal circumstances) be delivered to consciousness as its intentional object, resulting in the mental state we call reading (intentionality, in the present context, refers to the proposition that all conscious states have content-that is, they are about something; e.g., Anscombe, 1965; Brentano, 1995; Textor, 2013). But (and this is a core contention of this article), the automatic

This article was published Online First May 11, 2015.

I thank Tim Lane and Dan Robinson for their penetrating insights, and Steve Lynn for unfailing support. I also thank Shaun Nichols for calling my attention to depersonalization as a case of compromised personal ownership.

Correspondence concerning this article should be addressed to Stan B. Klein, Department of Psychological and Brain Sciences, 551 Ucen Road, University of California at Santa Barbara, Santa Barbara, CA 93106. E-mail: klein@psych.ucsb.edu and flawless manner in which consciousness takes possession of its intentional objects masks a fundamental relation-specifically, the relation that enables a person to prereflectively experience his or her mental states as personally owned.

In this article my interest is with the experiential aspects of mind (e.g., Klein, 2015a). In particular, I present empirical evidence and conceptual argument for a mechanism (or mechanisms) that enables consciousness to take ownership of its intentional objects (where ownership entails a sense of personal possession that, at least under normal circumstances, is prereflective-see "Personal and Perspectival Ownership" below). Such a mechanism has not, in my opinion, received sustained analysis in psychological treatments of the mind-though it has been accorded an increasingly prominent role in the interpretation of certain psychopathologies (e.g., Bortolotti \& Broome, 2009) as well as the philosophy of mind (e.g., Lane, 2012). The goal of this article is to make the case for a need to devote greater attention to an aspect of experiential reality that has significant implications for normal, as well as the dysfunctional, workings of the mind.

But, do we really need to add another process to the arsenal of hypothetical entities with which psychologists populate the mind? Especially one whose superfluity seems so evident? After all, isn't it little more than "a penetrating glimpse into the obvious" to ar- 
gue that my feeling of ownership consists in the fact that my mental states take place in me (i.e., in my head)? Isn't one's personal ownership guaranteed by one's personal perspective? Is there a pressing need to add to the mental clutter by postulating what seems a mechanism based on a tautology?

To put things bluntly-Yes! As I hope to show, perspective-based inference is found seriously wanting when the ownership relation fails - that is, in cases of psycho- and neuropathology (see "Functional Independence of Content and Ownership: The Experienced Loss of Personal Ownership in Cases of Clinical Pathology" and "Functional Independence of Content and Ownership: The Experienced Loss of Personal Ownership in Cases of Nonclinical Pathology" below). Under these circumstances, perspective is insufficient to underwrite feelings of personal ownership. In what follows I present both conceptual and empirical arguments in support of the need to posit a separate mechanism that enables consciousness to take ownership of its intentional objects.

Before proceeding let me be very clear on an important point. My interest is in the mechanisms that sanction an individual's feeling of epistemic authority in questions of personal ownership. As will be see in "Functional Independence of Content and Ownership: The Experienced Loss of Personal Ownership in Cases of Clinical Pathology" and "Functional Independence of Content and Ownership: The Experienced Loss of Personal Ownership in Cases of Nonclinical Pathology," a person may be confused or mistaken about the origins of his or her mental states. But, from a (bio)logical perspective, those states belong to the individual, whether s/he knows it or not: They are the products of his or her mind. In this article I am concerned with the former sense of personal ownership - that is, the mechanisms that enable a person to take noninferential possessory custody of mental states that, of ontological necessity, are authored by the person (though s/he might no longer know it).

\section{Key Terms and Their Definitions}

Because readers are likely to be unfamiliar with terms such as personal and perspectival ownership (concepts seldom voiced outside cer- tain Eastern philosophical traditions; e.g., Albahari, 2006), I first explain what I have in mind for some of the terms that play a central role in this article. Although not everyone will agree with my definitions, this exercise should leave little doubt about the meanings I intend. In what follows, several terms and their (perhaps idiosyncratic) meanings are presented in approximate order of their appearance in the text.

\section{Consciousness}

Consciousness is a topic whose explication (much less existence) has been the target of scholarly discourse for thousands of years. Despite the optimistic claims of some (e.g., emergent materialists), continuing struggles with this topic show little evidence of any imminent resolution. Analysis of consciousness has impressed upon investigators the need to partition the term into a variety of types and subtypesfor example, access consciousness, phenomenal consciousness, state consciousness, primary consciousness, temporal consciousness, core consciousness, reflective consciousness, primary consciousness, sentience, noetic awareness, autonoetic awareness, creature consciousness, higher order thought, pure consciousness, self-awareness, and so forth.

Although I appreciate the conceptual utility of many of these designations, my use of the term "consciousness" consists in the proposition that $\mathrm{X}$ is a state of consciousness if and only if there is "something it is like" for the organism to be in that state (e.g., Nagel, 1974). That is, consciousness, as I use the term, consists in first-person subjectivity. This usage is what most philosophers have in mind when discussing phenomenal consciousness (e.g., Chalmers, 1996; Strawson, 2009a), although a precise definition of "what it is like to be in a particular state" has proven to be notoriously difficult (e.g., Block, 1995). Phenomenal consciousness is perhaps best understood from the perspective of personal acquaintance (e.g., Russell, 1912/1999; for discussion, see "Two Paths to Knowledge" below).

\section{Mental States and Mind}

A mental state consists in representational content (i.e., an intentional object) and its conscious apprehension. The resulting mental states 
are individuated by both the properties of the intentional object (e.g., facts, images, propositions) and features associated with the type of consciousness to which content is presented (as noted, in this article I will be concerned primarily with phenomenal consciousness). For example, the same content (e.g., information about one's home) can result in the mental state of episodic recollection (when the intentional object is conjoined with autonoetic consciousness) or of knowledge (when it is apprehended by noetic consciousness). Mental states comprise the great variety of psychological faculties familiar to both academic discourse and personal phenomenology (e.g., attitudes, belief, memory, imagination, thought, inference, etc.; for discussion, see Klein, 2015b).

Importantly, a mental state is the subjectively experienced outcome of subexperiential processes taking place in the brain. These subexperiential processes consist in various learned and inherited subroutines and decision rules (e.g., Klein, Cosmides, Tooby, \& Chance, 2002) that act on stored content to enable the judgments, thoughts, inferences, plans, decisions, and so forth we experience as (and enact in virtue of) our mental states. Although subexperiential processes are necessary preconditions for having a mental state, they are nonmental: They are the neural mechanisms that enable experience, not the experience itself. They conceivably could go on without there being any subjective experience. An analogy may help: While a play consists in a great many behind the scenes activities (securing funding, finding a venue, etc.), strictly speaking, none of these activities is the play itself. On this view, the mind is the collection of subexperiential processes required for having a mental state and the mental states that they enable. ${ }^{1}$

\section{Personal and Perspectival Ownership}

By personal ownership I mean that one's experiences are felt as belonging to oneself. The appropriation of the content of experience to one's self is noninferential and prereflective (i.e., directly given as "mine”). In James' (1890) colorful terms, personal ownership is accompanied by the feeling that one's experiential content is imbued with a sense of warmth and intimacy.
Given the effortless manner in which the felt ownership of mental states typically unfolds, we seldom are aware an ownership relation between consciousness and its content needs to be forged. However, as we will see in "Functional Independence of Content and Ownership: The Experienced Loss of Personal Ownership in Cases of Clinical Pathology" and "Functional Independence of Content and Ownership: The Experienced Loss of Personal Ownership in Cases of Nonclinical Pathology" below, in certain clinical conditions (e.g., depersonalization, thought insertion, somatoparaphrenia), intentional objects can be present in awareness, yet lack the feeling that they are owned by consciousness. When this occurs, the content that serves as the intentional object is treated as alien to the self. Even when the afflicted individual accepts that he or she must have authored the phenomenologically unowned content (e.g., although I acknowledge that I produced the thought in my head, it is not mine. I was forced to think it by an alien, divine intervention, or the mind control machine in the basement of the CIA), the content is accompanied by nagging feelings of personal disconnectedness (see "Functional Independence of Content and Ownership: The Experienced Loss of Personal Ownership in Cases of Clinical Pathology" and "Functional Independence of Content and Ownership: The Experienced Loss of Personal Ownership in Cases of Nonclinical Pathology" below).

In these ways, the ordinarily hidden relation between experienced content and personal ownership, in virtue of it absence, is thrust into view. Personal ownership can be seen as the "mental glue" that experientially binds the two core properties of a mental state (content and its conscious apprehension; see "Mental States and Mind" above) into a sense of oneness (i.e., $m y$ content).

In contrast, perspectival ownership of one's mental states is not a directly given, prereflective aspect of occurrent experience. Rather, it is based on inferential knowledge-specifically,

\footnotetext{
${ }^{1}$ Great care must be exercised here. Cerebral blood flow and neuro-cellular metabolism also are subexperiential processes whose integrity is essential to having a mental state. But it would seem a conceptual over-reach to classify such things as aspects of mind. Boundaries need to be drawn, but the borders (at present) are far from clear.
} 
knowledge that my mental states appear in a manner different from that in which they appear to anyone else-that is, they are in my head. Content present to experience in this manner does not guarantee the experiencer will (or can) assume ownership of the content (see "Functional Independence of Content and Ownership: The Experienced Loss of Personal Ownership in Cases of Clinical Pathology" and "Functional Independence of Content and Ownership: The Experienced Loss of Personal Ownership in Cases of Nonclinical Pathology" below).

In sum, what individuates a mental state as distinctly and exclusively my own is that I intuitively sense-without a need for intuition, inference, or reflection-that the content of that mental state is uniquely and infallibly my content (for detailed discussions, see Albahari, 2006; Klein, 2012, 2013; Lane, 2012, 2014; Shoemaker, 1984; Zahavi, 2011). This form of ownership is the focus of the present article.

\section{Functional Independence}

The contention that two processes, systems, or mechanisms (i.e., $\mathrm{X}$ and $\mathrm{Y}$ ) are functionally independent does not imply that $\mathrm{X}$ has nothing to do with $\mathrm{Y}$ or that they are completely separate. Rather, as Tulving (1983, p. 66), discussing systems of memory, explains, functional independence means that "one system can operate independently of the other, though not necessarily as efficiently as it could with the support of the other intact system." In this article, I attempt to demonstrate that consciousness and its intentional objects are functionally independent: Although their joint presence is necessary for having a mental state, consciousness and content are not ontologically coextensive.

\section{A Brief look at the Basic Model, Its Implications for Personal Ownership, and the Organization of the Argument for Personal Ownership}

A core connection of this paper is that a mental state is the experienced outcome of the conjoining of content and consciousness. Although the mental states that result from this interaction are determined by subexperiential (primarily neuro-cognitive; but see footnote 1) activity, these are preconditions for the state, not the state itself. That is, there is no mental state (e.g., memory, knowledge, imagination, belief, etc.) until content is made available to, and apprehended by, consciousness (e.g., Klein, 2012, 2015a; Neuhouser, 1990). In this sense, the commonly held assumption that there are subexperiential systems capable of being designated as, say, memory or imagination is called into question.

This is not to say there are no neural modules (in the Fodorian, sense; e.g., Fodor, 1983) with dedicated functions at the subexperiential level. Rather, the argument is that the output of those modules remains state-neutral until it is acted on by consciousness. Thus, the same subexperiential system may play role in movements that enable "swinging a golf club" or "reenacting a hole-in-one." But the output of that system does not become "an athletic performance" or "a behavioral manifestation of memory" until it becomes the intentional object of consciousness.

An example may help. Consider the mental state we call "memory." To experience a memory is to experience the product(s) of a sequence of subexperiential processes (e.g., encoding, storage and retrieval). But memory is not coextensive with these subexperiential processes. Rather, the outcome of subexperiential processing "becomes" memory only when the content it produces is taken by consciousness in a specific way (for fuller discussion, see Klein, 2013, 2015b).

For example, depending in part on the context in which the object is given to consciousness, the same content could be experienced as imagination, thought, belief, and so forth (for a detailed discussion see Klein, 2015b). On this view, there are no subexperiential systems specifically dedicated to specific types of memory: The type of memory experience one has (e.g., episodic or semantic) is realized only once consciousness takes state-neutral content in a particular way (e.g., autonoetically or noetically).

We thus need to distinguish the preconditions that enable first-person experience from the experience itself. Before being associated with a particular form of consciousness under particular circumstances, stored content is stateneutral-that is, it is agnostic with regard to the mental state in which it will participate: The same content can eventuate in the mental states we call imagination, thought, planning, belief, attitude, hope, and so on, as well as in memory. 
(To avoid potential confusion, let me be clear that the individuation of a mental state as, say, a memory, thought or a belief is a function of a variety of factors - including, but not limited to, the nature of the intentional object as well as the type of consciousness and the subexperiential routines enacted on the intentional object. Personal ownership enables one to experience possessory custody of a mental state: It is not a determining factor in the type of state experienced.)

Recently I have argued that a model of mind-in which the notion of preexisting neural networks dedicated to producing specific mental states is replaced by the view that subexperiential processes produce state-neutral content that is psychologically individuated (e.g., as memory, thought, imagination) only after being acted on by consciousness - can help us better understand both memorial (e.g., Klein, 2013, 2015b) and self-referential (e.g., Klein, 2012, 2014a) experience. Although a detailed treatment of this model would take us far from of our goal (i.e., making the case for a mechanism of personal ownership), in the next section I briefly discuss the core constituents of a mental state (content and consciousness). A rudimentary understanding of the way in which these components relate to each other provides the conceptual scaffolding necessary to support the arguments I subsequently advance for a mechanism of personal ownership.

A basic understanding of the ontological commitments of these constituents also will help us appreciate the methods and procedures required to tackle the complex issue of how mental states are known ("Mental States" below). In "Functional Independence of Content and Ownership: The Experienced Loss of Personal Ownership in Cases of Clinical Pathology" and "Functional Independence of Content and Ownership: The Experienced Loss of Personal Ownership in Cases of Nonclinical Pathology" below, I draw on these methods to document what happens when the mechanisms supporting feelings of personal ownership go wrong. Finally, I discuss some implications of these findings and suggest several domains in which a theory of personal ownership might help us make sense of puzzling clinical phenomena.

\section{Mental States: Consciousness and Its Intentional Objects}

Although it is well-beyond the scope of this article to provide a detailed treatment of the relation between content and consciousness, suffice it to say that, on the basis of both current empiricism and rational analysis, these two aspects of mind cannot be deduced from, or reduced to, a single, underlying principle, structure, process, substance, or system (e.g., Earle, 1972; Klein, 2012, 2014a; Nagel, 2012; Strawson, 2009a; Zahavi, 2005). One-the subexperiential processes that eventuate in the content presented to consciousness-are materially (primarily neural) instantiated, and therefore can, at least in principle, be objectified and quantified (e.g., Klein, 2012, 2014a). Accordingly, the processes responsible for the content of consciousness are capable of being treated as objects of scientific inquiry.

The other-first-person subjectivity-is the aspect of mind that experiences the intentional objects made available. It thus is the subject, rather than the object, of experience. As will be argued below, subjectivity cannot directly be known by acts of inference or analysis. Knowledge of our personal subjectivity is not something that can adequately be captured by propositional truths (i.e., descriptive analysis); rather it is a matter of direct acquaintance (e.g., Earle, 1972; Kant, 1998; S. Klein, 2012; McGinn, 2004; Robinson, 2008; Nagel, 1974; Russell, 1912/1999).

These considerations have important consequences for mental states as the focus of scientific inquiry. As introductory texts on psychology and neuroscience make abundantly clear, considerable progress has been made describing the subexperiential bases of mental states. This is because such mechanisms can be objectified and quantified, thus rendering them amenable to scientific analysis (at least what remains of them following conceptual reduction; e.g., Klein, 2015a). By contrast, consciousness still is too poorly understood to provide the definitional clarity required to situate it securely within a descriptive framework. Indeed, the difficulties encountered have left some wondering whether a satisfying conceptual treatment is possible in practice or in principle (e.g., Husserl, 1964; McGinn, 1991, 2004; Klein, 2014a; Nagel, 2012; Robinson, 2008). 
Not surprisingly, researchers (intentionally or otherwise) often attempt to side-step these difficulties by relying on readers' familiarity with terms such as "consciousness" and "subjectivity" (derived from years of knowledge by acquaintance; see subsection "Two Paths to Knowledge") to confer a sense of confidence that he or she knows what it is to which the researcher refers. But the problem remains: Careful analysis of the epistemological warrant of a purely theoretical rendition of first-person subjectivity reveals we largely are in the dark concerning what it is we are referring to when we attempt to describe what we mean by the word "consciousness" (e.g., Klein, 2012; McGinn, 2004; Robinson, 2008; Russell, 1913/ 1992; Varela et al., 1993).

Equally problematic, any attempt to treat consciousness as the object of scientific scrutiny has the consequence of stripping it of its core feature-its subjectivity (e.g., Earle, 1972; Klein, 2012, 2014a, 2015a; Robinson, 2008; Midgley, 2014). When objectivity ${ }^{2}$ is the stance adopted by subjectivity to study itself - that is, when consciousness takes itself as its intentional object - subjectivity must, of logical necessity, be directed toward some "other" that serves as its object (e.g., Earle, 1972; Husserl, 1964; Klein, 2012; Neuhouser, 1990; Rossman, 1991; Zahavi, 2005). Thus, to study first-person experience as an object, one first must transform it into a third-person entity.

Paradoxically, the subjective aspect of the mind can achieve objectivity only at the cost of forfeiting its essence as the mind's subjective center (e.g., Earle, 1955; Gallagher \& Zahavi, 2008; Klein, 2012; Varela, Thompson, \& Rosch, 1993). Once apprehended as an object by first-person subjectivity (one's own or that of another), consciousness becomes an object in the manner all objects (mental and physical) become when objectified and quantified (e.g., Husserl, 1964; Klein, 2014a; Neuhouser, 1990). In the process, the subjective core of the firstperson experience is lost.

Science trades in the world of publically observable and physically measureable objects and events (e.g., Earle, 1955; Hanson, 1958, 1971; Margenau, 1950; Rescher, 1984, 1997). Bridging laws - which, despite attracting the critical attention of philosophers (e.g., Hempel, 1965), continue to have considerable traction in psychology (e.g., Klee, 1997)—play an impor- tant role in this enterprise, providing a theoretic device by which investigators construct logically defensible mappings of observables to theory (e.g., Klee, 1997; Ladyman, 2002; Margenau, 1950). But, as we have seen, for consciousness to become part of scientific inquiry, it first has to relinquish its subjectivity. To maintain its integrity, subjectivity cannot be transformed into an object (e.g., Husserl, 1964; Kant, 1998; Klein, 2012; Rossman, 1991; Zahavi, 2005; but see Strawson, 2009b, for a dissenting view). Yet, absent objective instantiation, bridging laws lack conceptual warrant, making it is hard to see how scientifically defensible questions about mental states can be formulated.

\section{So, How Can We Know Our Mental States? Two Paths to Knowledge}

If reducing first-person experience to objective, quantifiable properties strips it of its subjectivity, how might one come to know the phenomenological realization of subexperiential activity? In earlier articles, I have suggested that Russell's (1912/1999, 1913/1992) distinction between two forms of knowledge - that by acquaintance and that by description-offers a potentially productive way of exploring the mental aspects of mind (consciousness and its objects) without having to (a) prioritize one form of knowing over the other, or (b) affect a conceptual reduction in which all properties of mind are forced to fit a single mode of knowing (e.g., Klein, 2010; Klein \& Gangi, 2010; see also McGinn, 2004).

Knowledge by acquaintance amounts to direct contact (perceptual or introspective) with things of which we are aware. To borrow Nagel's (1974) provocative phrase, we know our mental states by our acquaintance with "what it feels like" to have those states. There is no need for intermediary steps such as "processes of inference or any knowledge of truths." (Russell, 1912/1999, p. 25). Nor are such steps epistemologically justifiable-since they have the consequence of reducing the aspect of reality under

\footnotetext{
${ }^{2}$ Objectivity is based on the assumption that an act or object exists independent of any one person's awareness of it (e.g., Earle, 1955; Martin, 2008; Nagel, 1974; Rescher, 1997). That is, it is something other than the self.
} 
investigation into a shadow of itself (e.g., Klein, 2015a; McGinn, 2004; Midgley, 2014).

Knowledge by description, in contrast, consists in the formulation of propositional "truths" about objects of inquiry. Although we can attempt to reduce our mental states to such formalizations (as many have; e.g., Blackmore, 2004; Edelman \& Tononi, 2000; Marcel \& Bisiach, 1988; Weber \& Weekes, 2009), doing so runs the serious risk of stripping consciousness of its phenomenological essence (e.g., Chalmers, 1996; Earle, 1955; Klein, 2015a; Nagel, 2012; Midgley, 2014; Robinson, 2008). Put differently, a purely conceptual analysis of experience, no matter how well crafted, is a discourse about, not a rendering of, experience (Klein, 2015a; Varela et al., 1993).

In sum, our knowledge of our mental states is based on our direct acquaintance with them: There is "something it is like" to have a mental state. On this point, Russell is adamant: It is only in virtue of knowledge by acquaintance that we know our mental states (see also, McGinn, 2004). Although we can propose conceptual "truths" about aspects of those states, this analytic reduction renders the target of the reduction less-than-whole (e.g., Gallagher \& Zahavi, 2008; Klein, 2015a). As Varela et al. (1993) observe, "When it is cognition or mind that is being examined, the dismissal of experience becomes untenable, even paradoxical. . . . To deny the truth of our own experience in the scientific study of ourselves is not only unsatisfactory; it is to render the scientific study of ourselves without a subject matter" (pp. 13-14). With mental states, experience (by acquaintance) comes first.

\section{Using Knowledge by Acquaintance to Explore the Mind}

Knowledge by acquaintance thus provides the palate we use to give color, form, and texture to our experiential landscape-a depiction not capable of full realization from a purely theoretical stance (e.g., Jackson, 1986; Russell, 1912/1999; Varela et al., 1993; Wallace, 2003). There simply is no other way to reliably know what a mental state, qua mental state, fully entails (e.g., Gertler, 2011; Jackson, 1986; Klein, 2015a; McGinn, 2004; Russell, 1912/ 1999).
This is not to say we have first-person access to all the processes and mechanisms (many of which operate outside awareness) logically required to support our mental states. In many (perhaps most) cases we do not (e.g., Nisbett \& Wilson, 1977). But we do have a privileged relation with the experienced outcomes of the subexperiential workings of mind. Accordingly, if you want to know about mental states, knowledge by acquaintance offers the only experientially defensible picture of its contours and colors. Reduction to mathematical formulas, propositional "truths," and other currently practiced tools of scientific objectification does more to obscure than to reveal the phenomenon of interest.

\section{Knowledge by Acquaintance: The Use of Introspective Techniques}

Strategies for treating experience as an irreducible, but knowable, aspect of reality already are available (though underutilized). Perhaps the most promising approach-sustainable within the context of our current methodological sophistication-relies on our uniquely human ability to introspect and put into words our acquaintance with our mental states.

Although introspective techniques have long been held to suffer from a variety of interpretive and methodological difficulties (for review and discussion, see Ericsson \& Simon, 1985), in recent years many of these concerns successfully have been addressed (e.g., Brewer, 1994; Hurlburt, 1990; Hurlburt \& Schwitzgebel, 2007). Accordingly, the use of introspective reports as a reliable and informative source of information about mental states has seen a resurgence over the past few decades (e.g., in domains such as autobiographical memory, self, consciousness, and temporal self-projection; e.g., Conway, Rubin, Spinnler, \& Wagenaar, 1992; Fivush \& Haden, 2003; Hurlburt, 1993; Klein, 2012; Nelson, 1989; Race, Keane, \& Verfaellie, 2011). This is attributable, in large part, to the unique perspective introspective data provide - that is, an empirically sanctioned and logically defensible vantage point from which to observe mental reality in the fullness in which it is given to experience (e.g., Klein, 2015a). Although translation of experience into words clearly has limitations, this currently is the best way to go when attempting to study the 
experiential aspects of reality (e.g., Hurlburt \& Schwitzgebel, 2007; Klein, 2014a).

\section{Personal Ownership: A Relation Between Consciousness and Its Intentional Objects}

In what follows, I make the case for a critically important, but conceptually underappreciated, relation between consciousness and its content. Specifically, I present evidence in support of the proposition that the mere presence of an intentional object in consciousness is not sufficient for that object to be felt as personally owned. What is needed is a mechanism by which the intentional object and consciousness are placed in an ownership relation, resulting in the prereflective feeling that the object I experience is "my" object.

Evidential support for this contention comes primarily from consideration of cases in which the ownership relation is compromised. Under these circumstances, the intentional object, despite occupying a unique position with respect to its conscious apprehension (i.e., it is in $m y$ head), no longer is experienced as personally owned. Although, at first blush, this may seem incoherent (after all, how can $m y$ consciousness take as its object content that is not also my own?), its plausibility is secured by the idea (see Sections "A Brief Look at the Basic Model ..." and "Mental States") that mental content is conceptually agnostic before being taken as an intentional object (e.g., Klein, 2013, 2015b). Subexperiential state-neutrality implies that prior to assuming the status of intentional object, content does not belong to any mental state, including the one we refer to as self (for recent discussions of the self, see Klein, 2012; Prebble, Addis, \& Tippett, 2013). On this view, personal ownership is not an intrinsic property of the intentional object ${ }^{3}$; rather, ownership requires that consciousness relate to its object in a particular, self-referential way (e.g., Klein, 2013, 2014b, c; Klein \& Nichols, 2012; Lane, 2012).

This, of course, opens the door to the possibility that, as a result of disruption of the mechanisms underwriting prereflective feelings of personal ownership, content mistakenly may be attributed to someone or something other than the self (e.g., Talland, 1964). Even when aspects of content-for example, facts about oneself-enable one to infer personal possession (see "Functional Independence of Content and
Ownership" below), inference-based ownership fails to afford the clarity and certitude provided by noninferential mechanisms of personal belonging (e.g., Klein, 2014c; Zemach, 1983).

\section{An Argument for the Need to Posit a Mechanism Capable of Forging an Ownership Relation Between Mental Content and Consciousness Based on a Reconstruction of the Hominid Mind}

Arguments in support of a mechanism enabling one to feel ownership of one's mental states are uncommon in psychology. The principle exception is found in literature on clinical conditions such as schizophrenic thought insertion and depersonalization (see "Functional Independence of Content and Ownership" below). Perhaps the only sustained discussion of personal ownership outside the clinical context is Jaynes' (1976) speculative interpretation of documents and artifacts dating back thousands of years. Based on his reading of the evidence, Jaynes concludes that the human mind, for much of its evolutionary history, did not consistently take its mental states (in particular, thoughts) as personally owned. Rather, our ancestors sometimes attributed such content to external agents-most often deities and demons.

Thinking leaves no fossil record. Accordingly, Jaynes' reconstructive analysis is susceptible to the claim that it represents little more than a very clever, but unwarranted, reading of the historical record. However, an analysis of the introspective reports of present-day individuals suffering from (a variety of) psychological dysfunctions provides backing for Jaynes' basic position (though not necessarily the mechanisms he proposed to account for the hypothesized decoupling of content and ownership).

\section{Functional Independence of Content and Ownership: The Experienced Loss of Personal Ownership in Cases of Clinical Pathology}

In this section, I draw on patients' introspective reports to bolster my argument for a mech-

\footnotetext{
${ }^{3}$ Formally, $\mathrm{X}$ is an intrinsic property of $\mathrm{Y}$ if $\mathrm{Y}$ 's having the property $\mathrm{X}$ does not consist in $\mathrm{Y}$ also having a relation $\mathrm{Z}$ to something else.
} 
anism that enables consciousness to take its intentional objects as personally owned. In (most of) the cases discussed, content remains present to consciousness, but the feeling that this content is "mine" no longer is present. That is, despite maintaining a clear sense of hosting a mental state (i.e., perspectival ownership), that state is not experienced as belonging to oneself.

Such findings lend considerable support to the inference that an intentional object can exist alongside (within?) first-person subjectivity, yet not be felt as owned. Though ownership may subsequently be inferred from considerations of perspective or from information contained within the intentional object, these inferences are less than convincing to the person making the inference. As will be seen below, the loss of direct, noninferential feelings of ownership is highly confusing and occasionally traumatic (for reviews, see Albahari, 2006; Klein \& Nichols, 2012; Lane, 2012; Stephens \& Graham, 2000).

In the next subsection I show how a number of distinct clinical phenomena acquire conceptual coherence when viewed as disruptions of personal ownership. However, while such data support the need to posit a mechanism capable of underwriting the ownership relation, the evidence presented is not free of controversy. Accordingly, in subsection "Functional Independence of Content and Ownership: The Experienced Loss of Personal Ownership in Cases of Nonclinical Pathology," I present examples of ownership pathology less susceptible to interpretive ambiguity. Although such "pure" cases are few in number (at least at present; e.g., Klein, 2012; Lane, 2012), their scarcity is more than compensated by the conceptual clarity they provide.

Evidence from frontal lobotomy. Psychosurgery in the form of prefrontal lobotomy consists in the surgical ablation of pathways linking the thalamus with parts of the frontal lobes (e.g., Freeman \& Watts, 1942). Although no longer practiced-it was conducted from the late 1930s through the early 1970s-its intent was to relieve patients of mental disorders that had been found resistant to what, at the time, were standard treatments.

In the days after surgical intervention, patients would report experiencing a reduction of premorbid symptoms (e.g., anxiety, depression), while showing no apparent decline in general intelligence or cognitive function. Personality remained largely intact, and the ability to recall the personal past was mostly unaffected (though patients often commented that they did not think of their past as often as they had before surgery).

One consequence of the procedure-particularly relevant for our discussion - was the effect it had on patients' feelings of self-concern (e.g., Robinson \& Freeman, 1954): Postsurgically, patients reported little or no interest in either their current or future circumstances. Some experienced a form of depersonalization (see subsection "Evidence From Depersonalization"), in which boundaries between self and nonself were experienced as fuzzy or, in some cases, lost entirely (e.g., Freeman \& Watts, 1942). Feelings of the self as a temporal continuant (i.e., personal diachronicity) also were reduced or eliminated (although the concept of personal diachronicity remained intact; e.g., Robinson \& Freeman, 1954).

These findings sanction the inference that lobotomy patients' personally relevant experience consists in largely (though not completely; e.g., the loss of diachronicity) intact access to self-referential content, paired with a lack of concern for, or an interest in, that content. This dissociation between the experience of, and concern about, one's intentional objects, although not identical to loss of ownership, certainly is suggestive. However, before pursuing an analogy between concern and ownership, it is important to recognize that the data presented are based almost entirely on clinical anecdote and observations collected for purposes far afield from questions of personal ownership. Moreover, although it appears reasonable to assume that the absence of self-concern reflects the patient's failure to take the content of awareness as personally owned, such an assumption is not logically mandated. In short, although findings from patients undergoing prefrontal lobotomy for the relief of psychopathological disorders are suggestive, they do not license strong inferences about loss of ownership.

More germane to questions of personal ownership is a particular aspect of the psychosurgical process-the finding that surgery often altered patients' reactions to pain without changing their ability to experience pain. That is, although lobotomy patients did not lose the sensation of pain, they experienced relief from 
the anguish such sensations typically cause (e.g., Freeman \& Watts, 1946, 1948). As a result of this serendipitous finding, psychosurgery was adopted as a medical procedure for alleviating the suffering associated with chronic organic pain (e.g., JAMA, 1950; Freeman \& Watts, 1946, 1948; Murphy, 1951; Nemiah, 1962; for review and critical discussion, see Raz, 2009). Because this procedure most often was conducted on individuals lacking attendant psychopathology (e.g., schizophrenia), these data are not subject to the interpretive issues arising from concerns about the effects of comorbidity on introspective offerings (see Section "Evidence From Thought Insertion"). Accordingly, they are better suited to providing an untainted view of the relation between content (i.e., pain) and personal ownership than are data obtained from reports of patients undergoing psychosurgery to alleviate symptoms of psychopathology.

The results of psychosurgery were relatively clear-patients simultaneously experienced pain while distancing themselves from the pain experience. This, in turn, is consistent with (though not demanding of) the inference that what is taking place in these individuals is not the absence of experienced content, but failure to imbue that content with a feeling of personal attachment. (Some may wonder whether hypnotic treatment of chronic pain warrants a similar interpretation. It does not. In the standard treatment of pain by hypnosis, what is changed the intensity of experience of pain, rather than attachment to that experience; e.g., Jensen \& Patterson, 2006).

Although instructive, studies of the effects of psychosurgery on pain were not designed with the purpose of testing personal ownership. Accordingly, one must exercise considerable caution drawing inferences from the data. Although it seems reasonable to interpret these findings as a disruption between content and ownership, the data require a considerable number of assumptions before such conclusions emerge.

Evidence from thought insertion. Evidence more directly in support of the idea that the feeling of ownership can be disrupted by psychopathology is found in the literature on schizophrenia. Of particular bearing is the phenomenon of thought insertion. Individuals experiencing thought insertion report that there is a thought in their head that they did not volun- tarily produce: That is, they do not take the thoughts as their own (e.g., Bortolotti \& Broome, 2009; Campbell, 2002; Frith, 1992; Hoerl, 2001; Martin \& Pacherie, 2013; for a review see Stephens \& Graham, 2000).

Unfortunately, the experiences of schizophrenic patients' often are delusional (e.g., Bleuler, 1911/1950; David \& Cutting, 1994; Frith, 1992). A delusion, roughly speaking, is a belief maintained without due sensitivity to the evidence for or against it, and without appropriate regard for the causes of the belief or for the consequences of holding it. This leaves reports of individuals suffering thought insertion open to the objection that the reported experiences are tainted, to some indeterminate degree, by aspects of psychopathology having little, if anything, directly to do with the experience of ownership. For example, a person suffering thought insertion may feel that a thought present in awareness is his or her own, but, as a consequence of a delusional mandate (or heightened self-protective concerns), be unwilling to publically acknowledge the content as "mine." Accordingly, such data, though, on the surface, consistent with the argument for a mechanism of personal ownership, cannot, by themselves, provide closure.

Evidence from anosognosia. Anosognosia is a well-documented pathology in which patients experience problems with memory, language, perception, or voluntary movement, but show either no awareness of the deficit or fail to acknowledge the deficit as their own (e.g., Babinski, 1914; McGlynn \& Kaszniak, 1991; Mograbi, Brown, \& Morris, 2009; for reviews see McGlynn \& Schacter, 1989 and Prigatano \& Schacter, 1991). ${ }^{4}$ While ansoagnosia can impact any part or parts of the body, for expositional convenience I restrict focus on its effects on bodily appendages. However, my arguments, with minor emendations, apply to anosagnosia in its broadest realizations.

From an ownership perspective, one wants to know what such patients make of their own behavior-given that they clearly can perceive the affected appendage, but don't acknowledge

\footnotetext{
${ }^{4}$ It is important to understand that these patients are not in denial of their deficits or indifferent to them (when a patient acknowledges a deficit but seems untroubled by it, the syndrome is called anosodiaphoria).
} 
its deficits (e.g., Ansell \& Bucks, 2006; Ataria, 2015; De Vignemont, 2007). Some patients attribute their inability to move a body part to arthritis or rheumatism; others, when asked to move an affected limb, appear distracted, move the unaffected limb, or respond that they have moved the affected limb, when in fact they have not (this happens even when the patient looks directly at the affected limb during examination).

Explanations can become bizarre or delusional. For example, a patient may claim that the affected limb is not his or her own, but rather belongs to someone else-for example, it was forgotten by a previous patient or belongs to someone lying by their side. One woman, studied by Bisiach and Geminiani (1991), was anosognosic for her hemiplegia. She claimed that her left hand did not belong to her; rather, it had been left in the ambulance by another patient. Another hemiplegic patient stated that his left arm belonged to the examiner. When the examiner placed the patient's left hand between his own arm and hands, the patient continued to deny that his arm was his own and attributed three arms and three hands to the examiner!

Viewed in terms of pathologies of personal ownership, these cases suggest a relatively uncompromised apprehension of the intentional object (e.g., an intact ability to mentally represent the affected body part-although this content often is compromised to a degree) existing alongside intact consciousness (e.g., the ability to take that content as an object of awareness). What has come undone is the link that enables content to be given directly and prereflectively to the consciousness as "mine": The person acknowledges the presence of an "afflicted" limb, but fails to experience that presence as indicative of personal ownership. Interestingly, in some of the cases mentioned, the patient seems unable to draw on rational inference to compensate for the loss of felt of ownership (e.g., the patient who believed the examiner possessed three hands).

Anosognosia represents a diverse collection of afflictions, varying both in the bodily (and mental-e.g., memory; Ansell \& Bucks, 2006) function compromised, and the extent to which the patient is able to acknowledge the presence of dysfunction. Although it typically is found in cases of neural damage or disease, it also occurs in cases of psychopathology (e.g., dementia, schizophrenia). Although the former (neural damage) are not necessarily troubling from an interpretive standpoint (such damage is not inevitably accompanied by comorbidity), the latter suggest that cases of anosognosia can be delusional and thus present some of the interpretive difficulties I raised with regard to thought insertion. In addition, the status of one's body image can be partially compromised by the disorder (e.g., Prigatano \& Schacter, 1991), making it difficult to ascertain the extent to which the designation of "intact" is an accurate description of the intentional object.

Evidence from depersonalization. A less contentious domain within which to seek evidence for the loss of personal ownership is the psychiatric syndrome known as depersonalization (e.g., Reutens, Nielson \& Sachdev, 2010; Sierra \& Berrios, 1997; Simeon, 2004; Simeon \& Abugel, 2006). Depersonalization-which can be transient or chronic-is characterized by a sense of detachment from one's self (e.g., Guralnik, Schmeidler, \& Simeon, 2000; Medford, Sierra, Baker, \& David, 2005). As described in the Diagnostic and Statistical Manual of Mental Disorders, fifth edition (DSM 5; American Psychiatric Association, 2013), persons experiencing depersonalization (a) feel detached from or outside of their body, (b) lack appropriation or attribution of mental states to the self, and (c) experience the self as empty and incomplete (see also Hunter, Phillips, Chalder, Sierra, \& David, 2003; Sierra \& Berrios, 1997; Simeon, 2004; Simeon \& Abugel, 2006). Functional neuroimaging has identified abnormal prefrontal activity in patients experiencing depersonalization (e.g., Phillips et al., 2001; reviewed in Medford et al., 2005), which, taken in conjunction with the findings from prefrontal lobotomy (subsection "Evidence From Frontal Lobotomy"), suggests neural substrates in the frontal cortex may play a role in the experience of loss of personal ownership (see also footnote 5).

Patients experiencing depersonalization report experiencing a persistent or recurrent sense of standing apart from both mind and bodythat is, feeling that their body and mental states do not belong to them. In such cases it appears that intact self-referential content exists in conjunction with functioning first-person subjectivity, albeit a subjectivity bewildered by the absence of felt ownership of the content of its experiences. As Albahari (2006, pp. 173-174) 
observes, depersonalized patients "realize there is something wrong and they wish the state and its attendant sensation would go away [italics in original] . . . the negative emotions arise because the person is in a situation he wishes was otherwise." Depersonalized patients thus appear to evidence an intact content and subjectivity conjoined with the absence of a feeling of a personal relation between these two mental state constituents.

Unfortunately for our purposes, chronic depersonalization (the more prevalent form of the disorder) is found primarily in individuals suffering comorbidities such as depression, schizophrenia, anxiety disorders and panic attacks (e.g., Medford et al., 2005; Reutens et al., 2010). Research has shown extensive comorbidity (in approximately $60 \%$ of patients) with Axis II personality disorders, including borderline, avoidant personality and obsessivecompulsive personalities (Simeon, 2004). In light of these attendant pathologies, testimony of individuals experiencing depersonalization inherits much of the same interpretive ambiguity plaguing previously presented cases (e.g., thought insertion and anosognosia).

\section{Functional Independence of Content and Ownership: The Experienced Loss of Personal Ownership in Cases of Nonclinical Pathology}

Although individuals experiencing psychosurgery, thought insertion, anosognosia, and depersonalization report a loss of personal ownership (e.g., of, pains, thoughts, body image, selfknowledge), issues of comorbidity render these findings analytically challenging. However, the discovery that ostensibly unrelated clinical conditions acquire a degree of interpretive unity when viewed through the lens of a common pathology gives credence to the argument that a mechanism of "personal ownership" has both epistemological utility and ontological warrant.

Fortunately there exist cases in which loss of ownership of one's mental states occurs in the absence of any apparent psychopathology. These "pure" or "untainted" cases constitute the strongest argument for a mechanism that enables consciousness to "own" its intentional objects. At present, such cases constitute a very small database (I suspect more will begin to be reported once "personal ownership" becomes recognized as a necessary constituent of mind; see also Lane, 2012). In the following subsections I present several "pure" cases.

Loss of felt ownership of one's body due to neural insult: somatoparaphrenia. Somatoparaphrenia is a condition in which the patient, as a consequence of brain damage, denies ownership of contralesional body parts (e.g., Gerstmann, 1942; Halligan, Marshall, \& Wade, 1995; Nightingale, 1982; Vallar \& Ronchi, 2009). Feelings of disownership range from a single limb to an entire side of the body. Afflicted individuals can visually monitor their sensory-motor function and form internal representations of compromised body parts (e.g., they do not experience neglect), but they disavow ownership of the affected parts. Even if presented unimpeachable evidence that a limb belongs to (and is thus is attached to) his or her body, the patient will typically produce elaborate confabulations to explain away the "facts." For example, one patient, on being shown that her disowned limb remained securely attached to her torso, replied "But my eyes and my feeling don't agree, and I must believe my feelings. I know they look like mine, but I can feel they are not" (Nielsen, 1938, p. 555). In most cases the disorder resolves over time and unowned mental content (i.e., representations of the body) reacquires its status as "my" content.

In sum, this deficit (though it is often associated with anosognosia, the two have been shown to be independent; e.g., Vallar \& Ronchi, 2009) is one of personal estrangement from the content given to awareness. Although the disorder is uncommon, its accompanying phenomenology clearly shows that the integrity of the feeling of owning one's mental states can be compromised by neural insult (most commonly, as cases presented in this and previous sections show, to the frontal and parietal cortices; see also footnote 5). This, in turn, adds weight to the argument that a mechanism tasked with underwriting a sense of personal ownership has ontological reality.

Loss of ownership of visually-mediated intentional objects. D.P. is a 23-year-old male who complained of "double vision" (Zahn, Talazko, \& Ebert, 2008). On examination, it was discovered that D.P. did not actually experience double vision-rather, he was able to see normally, but "he did not immediately recognize that that he was the one who perceives and that 
he needed a second step to become aware the he himself was the one who perceives the object" (Zahn et al., 2008, p. 398). This "second step" consisted in the use of inference-that is, he relied on personal perspective (i.e., location in my head) to surmise that his perceptual experiences were his own.

Although diagnosed with right inferior temporal hypometabolism dysfunction of the right parieto-occiptal junction and precentral cortex, in all other respects D.P. appeared psychologically healthy. He suffered no psychosocial stressors or trauma and socially was welladjusted. A structured Diagnostic and Statistical Manual of Mental Disorders, fourth edition, text revision $(D S M-I V-T R)$ interview disclosed no evidence of psychopathology. Additional testing revealed normal memory performance, visual object recognition, lexical retrieval, attention and executive function. Importantly, his visual perception was unaccompanied by delusion, thought insertion, obsessive doubt, compulsion, or fear. In short, D.P. presented normally in every regard save one-he experienced a loss of personal ownership of visually acquired intentional objects.

D.P.'s pattern of spared and preserved function is consistent with the proposition that although the content of visual perception was experienced first-personally, this content no longer was taken as personally owned. Any sense of ownership required a "second step" based on rational reconstruction. D.P.'s introspective reports (which are not subject to by concerns about comorbidity) thus offer strong support for an ontological correlate of the hypothesized mechanism of personal ownership.

Shared states but distinct ownership: Craniopargus. Craniopargus is a rare disorder (about 1 in every 2.5 million, relatively few of whom survive) in which twins are born joined at the head. In an extremely unusual case (even by Craniopargus standards), Krista and Tatiana Hogan's attachment extended beyond fused skulls to include a neural bridge connecting the thalamus of one sister to that of the other (details of the case are reported in Dominus, 2011). In all other respects the twins appear physically healthy and socially well-adapted (especially remarkable given the social challenges they faced). Each girl had her own body and, despite some volumetric asymmetry between left and right hemispheres, their neuro- cognitive function appeared intact (though lagging slightly behind developmental milestones).

Of particular interest are the twins' reported experiences of each others' thoughts and perceptions. Some examples: (a) Tatiana was handed a toy bird in such a way that only she could see and touch the toy. Nonetheless, Kristina was able to report that Tatiana had received a toy bird. (b) When Tatiana was briefly touched on a bodily location out of her sister's line of sight, Kristina could point exactly to the spot on her sister's body where the touch occurred.

In short, Kristina can correctly attribute shared experience (e.g., feeling of possession, feeling of touch) to her sister (and Tatiana can do the same). That is, the twins correctly ascribe occurrent mental states to the person in whom the states originated. Kristina does not say "I have a toy bird" or that "I have been touched"; rather, she says that Tatiana has the toy bird and Tatiana has been touched. Placed in the context of the ideas developed in this article, the twins report conscious apprehension of the same intentional object (which presumably is shared between them via the thalamic bridge), but personal ownership of that object is felt as a property only of the twin for whom the mental state has sensory priority.

Because of their age (they were only 4 years old when covered by the New York Times), controlled studies of the twins have yet to be conducted. However, the evidence available is compelling and consistent with the view that each twin is capable of being introspectively aware of the other's mental states while also being aware that those states are not her own. Taken in conjunction with other evidence presented in "this and the preceding section," this finding is in strong opposition to the thesis that any mental state of which one is introspectively aware must be felt to be personally possessed (see also "Philosophical Considerations" below). That is, ownership is not an intrinsic property of mental states.

Loss of personal ownership of one's memory. This rather unique form of memory impairment—intact retrieval of learned content absent a feeling of personal ownership- - has, to my knowledge, previously been documented in only three cases (although felt loss of memory ownership occasionally is reported by patients experiencing depersonalization; e.g., Sierra, 
Baker, Medford, \& David, 2005). In one (very brief) report by Talland, 1964), the patient examined could accurately report the content of his memory experiences, but was unable to experience that content as his own (despite its subjective location in his head).

A second case (Davidson et al., 2008) consists in its entirety of mention that patient S.M. (who was part of a group of individuals with lesions in the parietal cortex - an area often found compromised in patients suffering loss of personal ownership) complained that she "often felt that she did not know where her memories had come from" (p. 1751). Although consistent with the proposition that her "memory" problem consisted in issues of content attribution rather than content retrieval, the brevity of the report renders its utility less-than-ideal.

Fortunately, there is a study for which extensive introspective reports are available-the case of patient R.B. (the details of this case are summarized herein; fuller treatment can be found in Klein, 2013, 2014c and Klein \& Nichols, 2012). Patient R.B., as a result of a being struck by a car while riding his bicycle, suffered severe injuries, including a crushed pelvis and the fracturing of most of the ribs on the left side of his torso. In addition to physical trauma, he experienced several cognitive impairments. These included mild aphasia and amnesia (both retrograde and anterograde) for events in temporal proximity to his accident. Performance on tests of verbal fluency and short-term memory (STM) fell slightly below scores provided by neurologically healthy, age-matched controls. R.B.'s psychological profile, in contrast, presented a clinically healthy and socially welladjusted individual.

While in the hospital, R.B. was placed on morphine (IV drip, followed by pills) and Oxycontin for relief from the considerable pain he endured. As the intensity of his pain subsided, he was weaned off medication. Importantly, at the time of testing R.B. was not on any pain medication. In addition, his long- and shortterm memory impairments, aphasia, and fluency deficits had resolved.

However, not all cognitive function returned. Specifically, although he could intentionally retrieve temporally and spatially situated events that had transpired in his past, those "recollections" were compromised in a very unusual manner: The events were unaccompanied by a sense of personal ownership. That is, R.B. was able to retrieve personal content from his past, but, like patient S.M., he did not feel the content belonged to him. In his own words, they lacked a sense of "personal ownership". As an example (more can be found in Klein \& Nichols, 2012), shortly following his release from the hospital, R.B. provided the following descriptions of what it was like for him to remember personal events:

I did not own any memories that came before my injury. I knew things that came before my injury. . . . I could answer any question about where I lived at different times in my life, who my friends were, where I went to school, activities I enjoyed. . . . But none of it was 'me.' [although, as he makes clear below, he can know they are his by an act of inference]

\section{Again:}

I could clearly recall a scene of me at the beach in New London with my family as a child. But the feeling was that the scene was not my memory ... the memories did not in any way feel like they were my memories.

Although R.B. can refer the content of his occurrent mental states in his past, to do so requires effortful, inferential processes (under normal, nonpathological circumstances, such reference is automatic; e.g., Klein, 2015b). For example, despite lacking the normal, prereflective feeling that an occurrent mental state is a reliving of his past (e.g., Klein, 2013, 2015b; Tulving, 1985, 2005), R.B. could accept that this content was "something that should belong to me." But, as the following introspective account makes clear, that knowledge was based on inferential reasoning rather than felt acquaintance:

I can picture the scene perfectly clearly . . . studying with my friends in our study lounge. But ... it does not feel like it was something that really had been a part of my life. Intellectually I suppose I never doubted that it was a part of my life. Perhaps because there was such continuity of memories that fit a pattern that lead up to the present time. But that in itself did not help change the feeling of ownership.

He continues:

Having been to MIT had two different issues . . my memories of having been at MIT I did not own. Those scenes of being at MIT were vivid, but they were not mine. But I owned 'the fact that I had a degree from MIT'. . . that might have simply been a matter of rational acceptance of fact. ... I remember eating pizza at XXX in Isla Vista, but the memory belongs to someone else. But knowing I like pizza, in the present, 
now, is owned by me. When I recall memories from my past, I intellectually know they are about me. It just does not feel like it.

Thus, R.B.'s memorial offerings were not given to consciousness as "mine." Instead, the connection had to be forged via conceptual analysis: He could infer that the content given to awareness must be from personal past experiences, but he did not know this in virtue of direct feelings of "mine-ness." In this regard, R.B.'s inferential efforts appear analogous to the "second step" used by patient D.P. (Zahn et al., 2008) to gain an appreciation that objects present in awareness were his perceptions.

R.B. eventually recovered his ownership abilities, at which time the same (or largely similar) content now automatically was taken by consciousness as a personally owned. This suggests that it was the mechanism(s) enabling personal ownership, not the content on which it acted, that was compromised by neuro-cognitive insult. R.B. describes his recovery of memory ownership as initially gradual, followed by abrupt reappropriation:

\footnotetext{
When I did 'take ownership' of a memory, it was actually quite isolated. A single memory I might own, yet another memory connected to it I would not own. It was a startling experience to have no rhyme or reason to which memories I slowly took ownership of, one at a time at random over a period of weeks and months. ... What happened over the coming months ... was interesting. Every once in a while, I would suddenly think about something in my past and I would 'own' it. That was indeed something 'I' had done and experienced. Over time, one by one, I would come to 'own' different memories. Eventually, after perhaps eight months or so, it seemed as if it was all owned . . . as if once enough individual memories were owned, it was all owned. For example, the MIT memory, the one in the lounge ... I now own it. It's clearly part of my life, my past.
}

It is important to note that during his "unowned" period R.B. had no difficulty retrieving specific, often one-of-a kind, personal experiences (e.g., being on a beach in New London). He had no trouble representing his body as being present at those experiences. He knew that the content in awareness was about him rather than, say, his mother. And he could call up, that is, auto-cue (e.g., Donald, 1991), memories at will. In this sense, his "memories" were both agentic and self-referential.

However, there appears to be another type of self-reference that typically accompanies recol- lection (ownership, mineness) that was impaired in his case. His deficit was in representing, in the first-person, that "I had these experiences." That is, his impairment entailed a loss of the ability to take personal possession of memory-based objects in awareness.

In summary, in each of the cases presented in this subsection, the primary constituents of a mental state (content and consciousness; see "Mental States" above) appear to maintain their integrity. However, a specific relation between these constituent-one of ownership-has been rendered inoperative, resulting in the experience of hosting, but not personally owning, one's mental states. This, in turn, implies that personal experience (contra James, Kant and many others) is not "stamped" with the quality of "mine-ness" (e.g., Klein, 2013, 2014c). Put differently, the ownership relationship between content and consciousness appears to be contingent rather than intrinsic (e.g., Klein, 2013, 2014a, c; Lane, 2012; Zahavi, 2011).

\section{Conclusions}

In cases involving disruption of personal ownership, the "mental glue" that normally cements consciousness to its content in a relation of "personal belonging" loses its potency. This uncoupling, in turn, provides strong evidence for (a) a theoretical separation between what is experienced and how it is experienced (as mine), and (b) the functional independence of the hypothesized constituents (consciousness and content) of the ownership relation.

No amount (or quality) of evidence can conclusively establish that a postulated entity has an ontological correlate. However, the number of cases in which diverse symptoms (e.g., thought insertion, somatoparaphrenia, depersonalization, memory disruption), when viewed through the lens personal ownership, acquire conceptual coherence strongly suggests that such a mechanism cannot be dismissed simply as a misguided failure to heed Occam's razorthat is, the stipulation that we admit no more mechanisms than are deemed minimally necessary to explain a phenomenon. The data are saying something real and important about the nature of mind, and the sooner what is being said is incorporated into our ontology of psychological mechanisms, the sooner we will be 
in a position to treat experiential reality with the fullness it deserves (e.g., Klein, 2015a).

The phenomenon of "disruption of personal ownership" also suggests that the hypothesized constituents of mental states-that is, consciousness and its objects ("Mental States" above)- have ontological warrant. Ownership logically entails a two-part relation between the owner and the owned. The demonstration that certain individuals experience mental content absent a feeling that this content belongs to "me," shows that this relation can come undone. And this, in turn, sanctions the conclusion that consciousness and its content are ontologically functionally independent aspects of mind. ${ }^{5}$

\section{Clinical Consideration: Hallucinations, Flashbacks, and Pain Asymbolia}

The notion of "loss of personal ownership" has implications for understanding clinical disorders other than those addressed in the text: In particular, both hallucinatory experience (for reviews, see Bentall, 1990; Freeman \& Garety, 2003; Larøi \& Woodward, 2007) and PTSD flashbacks (for reviews see Brewin, Gregory, Lipton, \& Burgess, 2010; Ehlers, Hackmann, \& Michael, 2004; Hackmann, Ehlers, Speckens, \& Clark, 2004) can be viewed, at least in part, as disruptions of personal ownership. A feature common to both pathologies is that the object given to awareness (in hallucinations, most commonly visual or auditory content; in flashbacks, content that reflect traumatic events that played a determinative role in PTSD etiology) is taken as not being personally owned (in hallucinatory experience, the voices "heard" and sights "seen" are attributed to sources external to the experiencing agent; in flashbacks, patients often experience the flashback as an actual event taking place now, rather than as a mental reliving of a previously experienced incident). An argument can be made that what is common to both pathological experiences is a failure of the relational mechanisms that prereflectively confer a sense of "mineness" on objects given to awareness.

A similar explanation can be fashioned for the very rare disorder known as pain asymbolia (e.g., Berthier, Starkstein, \& Leiguarda, 1988; Rubins \& Friedman, 1948; Schilder \& Stengel, 1928, 1931; for a recent review see Grahek, 2007). Patients experiencing asymbolia report that they are aware that they are in pain-that is, they feel it—but they are indifferent to it. As Schilder and Stengel (1928) note: "The patient displays a striking behavior in the presence of pain. She reacts either not at all or insufficiently to being pricked, struck with hard objects, and pinched. She never pulls her arm back energetically or with strength. She never turns the torso away or withdraws with the body as a whole. She never attempts to avoid the investigator" (p. 147).

Despite failing to react to pain-inducing stimuli, asymbolics recognize what they feel as pain: "Pricked on the right palm, the patient smiles joyfully, winces a little, and then says, 'Oh, pain, that hurts.' She laughs, and reaches the hand further toward the investigator and turns it to expose all sides. . . . The patient's expression is one of complacency. The same reaction is displayed when she is pricked in the face and stomach" (Schilder \& Stengel, 1928, p. 147).

In short, asymbolia patients are both attentive to and aware of painful stimuli (e.g., Grahek, 2007). What they lack is the affectivemotivational component that normally accompanies pain experience: The patient no longer seems to care (e.g., Lane, 2014). Put into the language developed in this article, persons experiencing asymbolia know that pains are taking place in their body, but no longer feel those pains are their own. Though admittedly speculative, this somewhat unconventional way of explaining pain asymbolia seems worth a serious look.

\footnotetext{
${ }^{5}$ There exists an abundance of neuro-anatomical data from radiological and lesion studies suggesting that different cortical structures participate in (a) the formation and retention of mental content and (b) its ownership by consciousness. In particular structures in the medial cortex appear to play a significant role in the production and storage of content (e.g., Frankland \& Bontempi, 2005; Fuster, 1999; Gabrieli, 1998; Nadel, \& Moscovitch, 1997; Nadel \& Peterson, 2013; Naya \& Suzuki, 2011; Squire, 2004), whereas the frontal and parietal cortices seem more heavily involved in personal ownership (e.g., Davidson et al., 2008; Piolino et al., 2007; Tulving \& Szpunar, 2012; Wheeler, Stuss, \& Tulving, 1997; Zahn et al., 2008). Although such data are consistent with the proposed individuation of content and ownership, at this stage they are best treated as suggestive.
} 


\section{Philosophical Considerations: Immunity to Error Through Misidentification}

Wittgenstein (1958) famously held that asking someone with a toothache "are you sure it's you who have pains?" (p. 67) is nonsensical. Although we may improperly identify the target of a mental state when the target is someone else (e.g., I hear a voice which I attribute to John-when, in fact, it was Bob that I heard), we are immune to such errors of identification when mental states are ascribed to the self. Although our interpretation of the content of our experience may be inaccurate (e.g., the sun travels around the earth; two parallel lines appear to be converging), we cannot be mistaken about to whom the experience belongs.

In subsequent work, Shoemaker (1968) developed Wittgenstein's observation into the now well-known proposition that first-person present-tense statements attributed to oneself are immune to error through misidentification. Although several variants of "immunity to error through misidentification" (IEM) have been recognized (for discussion see Pryor, 1999), the take-away message for our purposes is that IEM, at least in its strong form, is false: Although a person may be unfailingly accurate in his or her judgment that $\mathrm{s} / \mathrm{he}$ experienced a mental state, possessory custody of that state (e.g., "it is my perception," "it is my memory," "it is my pain") can be compromised (as the cases reviewed in "Functional Independence of Content and Ownership: The Experienced Loss of Personal Ownership in Cases of Clinical Pathology" and "Functional Independence of Content and Ownership: The Experienced Loss of Personal Ownership in Cases of Nonclinical Pathology" above show). Accordingly, we may be immune to error in the sense that "I am experiencing X mental content," but we certainly are not immune to error in the sense that "The mental content I am experiencing belongs to me."

\section{A Word of Caution}

Let me end with a word of caution. Although the introspective reports from a variety of sources converge on the conclusion that content in consciousness is not automatically given as "owned," the ontological status of any hypothesized entity needs to be treated with a consid- erable degree of conceptual prudence. The methods that currently dominate psychology do not (and perhaps cannot; e.g., Gendlin, 1962; Martin, 2008; Klein, 2012) tap directly into the heart of our discipline-experiential reality (e.g., Klein, 2015a). And it is unreasonable to expect that we can erase our ignorance by relying on method and theory unsuited to taking experience in the fullness in which it is given.

Quite possibly, new methods will be needed (e.g., Gallagher \& Zahavi, 2008; Gendlin, 1962; Klein, 2012, 2015a; Martin, 2008). If psychology is successfully going to fulfill one of its core missions-to tackle the subjective aspects of the mind-reliance on objectification and quantification likely will need to be supplemented with methods better-fitted to capturing the phenomenological richness conferred by acquaintance with our mental states (e.g., Klein, 2015a).

\section{References}

Albahari, M. (2006). Analytical Buddhism: The two-tiered illusion of self. Houndsmills, UK: Palgrave Macmillan. http://dx.doi.org/10.1057/9780230800540

American Psychiatric Association. (2013). Diagnostic and statistical manual of mental disorders (5th ed.). Washington, DC: American Psychiatric Publishing.

Anscombe, G. E. M. (1965). The intentionality of sensation. In R. J. Butler (Ed.), Analytical philosophy, second series (pp. 158-180). Oxford, UK: Blackwell Publishers.

Ansell, E. L., \& Bucks, R. S. (2006). Mnemonic anosognosia in Alzheimer's disease: A test of Agnew and Morris (1998). Neuropsychologia, 44, 1095-1102. http://dx.doi.org/10.1016/j.neuropsy chologia.2005.10.019

Ataria, Y. (2015). Sense of ownership and sense of agency during trauma. Phenomenology and the Cognitive Sciences, 14, 199-212. http://dx.doi .org/10.1007/s11097-013-9334-y

Babinski, J. (1914). Contribution a l'etude des troubles mentaux dans 1 'hemiplegie organique cerebrale (anosognosie) [Contribution to the study of mental disturbance in organic cerebral hemiplegia (anosognosia)]. Revista de Neurologia, 1, 845848.

Bentall, R. P. (1990). The illusion of reality: A review and integration of psychological research on hallucinations. Psychological Bulletin, 107, 82-95. http://dx.doi.org/10.1037/0033-2909.107.1.82

Berthier, M., Starkstein, S., \& Leiguarda, R. (1988). Asymbolia for pain: A sensory-limbic disconnec- 
tion syndrome. Annals of Neurology, 24, 41-49. http://dx.doi.org/10.1002/ana.410240109

Bisiach, E., \& Geminiani, G. (1991). Anosognosia related to hemiplegia and hemianopia. In G. P. Prigatano \& D. L. Schacter (Eds.), Awareness of deficit after brain injury: Clinical and theoretical issues (pp. 17-39). New York, NY: Oxford University Press.

Blackmore, S. (2004). Consciousness. Oxford, UK: Oxford University Press.

Bleuler, E. (1911/1950). Dementia praecox or the group of schizophrenias (J. Zinkin, Trans.). New York, NY: International University Press.

Block, N. (1995). On a confusion about the function of consciousness. Behavioral and Brain Sciences, 18, 227-287. http://dx.doi.org/10.1017/ S0140525X00038188

Bortolotti, L., \& Broome, M. (2009). A role for ownership and authorship in the analysis of thought insertion. Phenomenology and the Cognitive Sciences, 8, 205-224. http://dx.doi.org/ 10.1007/s11097-008-9109-z

Brentano, F. (1995). Descriptive psychology. London, UK: Routledge.

Brewer, W. F. (1994). Autobiographical memory and survey research. In N. Schwarz \& S. Sudman (Eds.), Autobiographical memory and the validity of retrospective reports (pp. 11-20). New York, NY: Springer-Verlag. http://dx.doi.org/10.1007/ 978-1-4612-2624-6_2

Brewin, C. R., Gregory, J. D., Lipton, M., \& Burgess, N. (2010). Intrusive images in psychological disorders: Characteristics, neural mechanisms, and treatment implications. Psychological Review, 117, 210-232. http://dx.doi.org/10.1037/a0018113

Campbell, J. (2002). The ownership of thoughts. Philosophy, Psychiatry, \& Psychology, 9, 35-39. http://dx.doi.org/10.1353/ppp.2003.0001

Chalmers, D. J. (1996). The conscious mind: In search of a fundamental theory. New York, NY: Oxford University Press.

Conway, M. A., Rubin, D. C., Spinnler, H., \& Wagenaar, W. A. (Eds.). (1992). Theoretical perspectives on autobiographical memory. London, UK: Kluwer Academic Publishers. http://dx.doi.org/ 10.1007/978-94-015-7967-4

David, A. S., \& Cutting, J. C. (1994). The neuropsychology of schizophrenia. Hillsdale, NJ: Erlbaum Publishers.

Davidson, P. S. R., Anaki, D., Ciaramelli, E., Cohn, M., Kim, A. S. N., Murphy, K. J., . . L Levine, B. (2008). Does lateral parietal cortex support episodic memory? Evidence from focal lesion patients. Neuropsychologia, 46, 1743-1755. http://dx .doi.org/10.1016/j.neuropsychologia.2008.01.011

De Vignemont, F. (2007). Habeas corpus: The sense of ownership of one's own body. Mind \& Lan- guage, 22, 427-449. http://dx.doi.org/10.1111/j $.1468-0017.2007 .00315 . x$

Dominus, S. (May 25, 2011). Could conjoined twins share a mind? The New York Times Magazine. http://www.nytimes.com/2011/05/29/magazine/ could-conjoined-twins-share-a-mind.html?

Donald, M. (1991). Origins of the modern mind: Three stages in the evolution of culture and cognition. Cambridge, MA: Harvard University Press.

Earle, W. (1955). Objectivity: An essay on phenomenological ontology. New York, NY: The Noonday Press.

Earle, W. E. (1972). The autobiographical consciousness. Chicago, IL: Quadrangle Books.

Edelman, G. M., \& Tononi, G. (2000). A universe of consciousness: How matter becomes imagination. New York, NY: Basic books.

Ehlers, A., Hackmann, A., \& Michael, T. (2004). Intrusive re-experiencing in post-traumatic stress disorder: Phenomenology, theory, and therapy. Memory (Hove, England), 12, 403-415. http://dx .doi.org/10.1080/09658210444000025

Ericsson, K. A., \& Simon, H. A. (1985). Protocol analysis: Verbal reports as data. Cambridge, MA: The MIT Press.

Fivush, R., \& Haden, C. A. (2003). Autobiographical memory and the construction of a narrative self. Mahwah, NJ: Erlbaum.

Fodor, J. A. (1983). Modularity of mind: An essay on faculty psychology. Cambridge, MA: MIT Press.

Frankland, P. W., \& Bontempi, B. (2005). The organization of recent and remote memories. Nature Reviews Neuroscience, 6, 119-130. http://dx.doi .org/10.1038/nrn1607

Freeman, D., \& Garety, P. A. (2003). Connecting neurosis and psychosis: The direct influence of emotion on delusions and hallucinations. Behaviour Research and Therapy, 41, 923-947. http:// dx.doi.org/10.1016/S0005-7967(02)00104-3

Freeman, W., \& Watts, J. W. (1942). Psychosurgery. Springfield, IL: Charles C Thomas.

Freeman, W., \& Watts, J. W. (1946, June 29). Pain of organic disease relieved by prefrontal lobotomy. The Lancet, 247, 953-955. http://dx.doi.org/ 10.1016/S0140-6736(46)91713-8

Freeman, W., \& Watts, J. W. (1948). Psychosurgery for pain. Southern Medical Journal, 41, 1045-1049. http:// dx.doi.org/10.1097/00007611-194811000-00018

Frith, C. D. (1992). The cognitive neuropsychology of schizophrenia. East Sussex, England: Erlbaum/ Taylor \& Francis.

Fuster, J. M. (1999). Memory in the cerebral cortex: An empirical approach to neural networks in the human and nonhuman primate. Cambridge, MA: MIT Press.

Gabrieli, J. D. E. (1998). Cognitive neuroscience of human memory. Annual Review of Psychology, 49, 
87-115. http://dx.doi.org/10.1146/annurev.psych .49 .1 .87

Gallagher, S., \& Zahavi, D. (2008). The phenomenological mind. New York, NY: Routledge.

Gendlin, E. (1962). Experiencing and the creation of meaning: A philosophical and psychological approach to the subjective. Evanston, IL: Northwestern University Press.

Gerstmann, J. (1942). Problem of imperception of disease and of impaired body territories with organic lesions. Archives of Neurology \& Psychiatry, 48, 890-913. http://dx.doi.org/10.1001/archneur psyc.1942.02290120042003

Gertler, B. (2011). Self-knowledge. New York, NY: Routledge.

Grahek, N. (2007). Feeling pain and being in pain. Cambridge, MA: MIT Press.

Guralnik, O., Schmeidler, J., \& Simeon, D. (2000). Feeling unreal: Cognitive processes in depersonalization. The American Journal of Psychiatry, 157, 103-109. http://dx.doi.org/10.1176/ajp.157.1.103

Hackmann, A., Ehlers, A., Speckens, A., \& Clark, D. M. (2004). Characteristics and content of intrusive memories in PTSD and their changes with treatment. Journal of Traumatic Stress, 17, 231-240. http://dx.doi.org/10.1023/B:JOTS $.0000029266 .88369 . f d$

Halligan, P. W., Marshall, J. C., \& Wade, D. T. (1995). Unilateral somatoparaphrenia after right hemisphere stroke: A case description. Cortex, 31, 173-182. http://dx.doi.org/10.1016/S00109452(13)80115-3

Hanson, N. R. (1958). Patterns of discovery: An inquiry into the conceptual foundations of science. Cambridge, UK: Cambridge University Press.

Hanson, N. R. (1971). Observation and explanation. San Francisco, CA: Harper \& Row, Publishers.

Hempel, C. (1965). Aspects of scientific explanation. New York, NY: Free Press.

Hoerl, C. (2001). On thought insertion. Philosophy, Psychiatry, \& Psychology, 8, 190-200.

Hunter, E. C. M., Phillips, M. L., Chalder, T., Sierra, M., \& David, A. S. (2003). Depersonalisation disorder: A cognitive-behavioural conceptualisation. Behaviour Research and Therapy, 41, 1451-1467. http://dx.doi.org/10.1016/S0005-7967(03)00066-4

Hurlburt, R. T. (1990). Sampling normal and schizophrenic inner experience. New York, NY: Plenum Press. http://dx.doi.org/10.1007/978-1-47570289-7

Hurlburt, R. T. (1993). Sampling inner experience in disturbed affect. New York, NY: Plenum Press. http://dx.doi.org/10.1007/978-1-4899-1222-0

Hurlburt, R. T., \& Schwitzgebel, E. (2007). Describing inner experience? Proponent meets skeptic. Cambridge, MA: The MIT Press.
Husserl, E. (1964). The phenomenology of internal time-consciousness. Bloomington, IN: Indiana University Press.

Jackson, F. (1986). What Mary didn't know. The Journal of Philosophy, 83, 291-295.

JAMA. (1950). Lobotomy for relief of pain. Journal of the American Medical Association, 142, 35-36. http://dx.doi.org/10.1001/jama.1950 .02910190037010

James, W. (1890). Principles of psychology (Vol. 1). New York, NY: Henry Holt and Company. http:// dx.doi.org/10.1037/11059-000

Jaynes, J. (1976). The origin of consciousness in the breakdown of the bicameral mind. Boston, MA: Houghton Mifflin.

Jensen, M., \& Patterson, D. R. (2006). Hypnotic treatment of chronic pain. Journal of Behavioral Medicine, 29, 95-124. http://dx.doi.org/10.1007/ s10865-005-9031-6

Kant, I. (1998). The Cambridge edition of the works of Immanuel Kant; Critique of pure reason (P. Guyer \& A. W. Wood, Trans.). New York, NY: Cambridge University Press.

Klee, R. (1997). Introduction to the philosophy of science: Cutting nature at its seams. New York, NY: Oxford University Press.

Klein, S. B. (2010). The self: As a construct in psychology and neuropsychological evidence for its multiplicity. Wiley Interdisciplinary Reviews: Cognitive Science, 1, 172-183.

Klein, S. B. (2012). The self and its brain. Social Cognition, 30, 474-518. http://dx.doi.org/10.1521/ soco.2012.30.4.474

Klein, S. B. (2013). Making the case that episodic recollection is attributable to operations occurring at retrieval rather than to content stored in a dedicated subsystem of long-term memory. Frontiers in Behavioral Neuroscience, 7, 3. http://dx.doi.org/ 10.3389/fnbeh.2013.00003

Klein, S. B. (2014a). The two selves: Their metaphysical commitments and functional independence. New York, NY: Oxford University Press.

Klein, S. B. (2014b). Sameness and the self: Philosophical and psychological considerations. Frontiers in Psychology, 5, 29. http://dx.doi.org/ 10.3389/fpsyg.2014.00029

Klein, S. B. (2014c). Autonoesis and belief in a personal past: An evolutionary theory of episodic memory indices. Review of Philosophy and Psychology, 5, 427-447. http://dx.doi.org/10.1007/ s13164-014-0181-8

Klein, S. B. (2015a). A defense of experiential realism: The need to take phenomenological reality on its own terms in the study of the mind. Psychology of Consciousness: Theory, Research, and Practice, 2, 41-56. 
Klein, S. B. (2015b). What memory is. Wiley Interdisciplinary Reviews: Cognitive Science, 6, 1-38. http://dx.doi.org/10.1002/wcs.1333

Klein, S. B., Cosmides, L., Tooby, J., \& Chance, S. (2002). Decisions and the evolution of memory: Multiple systems, multiple functions. Psychological Review, 109, 306-329. http://dx.doi.org/ 10.1037/0033-295X.109.2.306

Klein, S. B., \& Gangi, C. E. (2010). The multiplicity of self: Neuropsychological evidence and its implications for the self as a construct in psychological research. Annals of the New York Academy of Sciences, 1191, 1-15. http://dx.doi.org/10.1111/j .1749-6632.2010.05441.x

Klein, S. B., \& Nichols, S. (2012). Memory and the sense of personal identity. Mind, 121, 677-702. http://dx.doi.org/10.1093/mind/fzs080

Ladyman, J. (2002). Understanding philosophy of science. New York, NY: Routledge. http://dx.doi .org/10.4324/9780203463680

Lane, T. (2012). Toward an explanatory framework for mental ownership. Phenomenology and the Cognitive Sciences, 11, 251-286. http://dx.doi.org/ 10.1007/s11097-012-9252-4

Lane, T. (2014). When actions feel alien-An explanatory model. In T.-W. Hung (Ed.), Communicative action (pp. 53-74). Singapore: Springer Science + Business Media.

Larøi, F., \& Woodward, T. S. (2007). Hallucinations from a cognitive perspective. Harvard Review of Psychiatry, 15, 109-117. http://dx.doi.org/ 10.1080/10673220701401993

Marcel, A. J., \& Bisiach, E. (1988). Consciousness and contemporary science. Oxford, UK: Oxford University Press.

Margenau, H. (1950). The nature of physical reality. New York, NY: McGraw-Hill.

Martin, C. B. (2008). The mind in nature. Oxford, UK: Oxford University Press.

Martin, J.-R., \& Pacherie, E. (2013). Out of nowhere: Thought insertion, ownership and contextintegration. Consciousness and Cognition, 22, 111-122. http://dx.doi.org/10.1016/j.concog.2012 .11 .012

McGinn, C. (1991). The problem of consciousness: Essays toward a resolution. Oxford, UK: Blackwell Publishers.

McGinn, C. (2004). Consciousness and its objects. Oxford, UK: Oxford University Press. http://dx .doi.org/10.1093/019926760X.001.0001

McGlynn, S. M., \& Kaszniak, A. W. (1991). Unawareness of deficits in dementia and schizophrenia. In G. P. Prigatano \& D. L. Schacter (Eds.), Awareness of deficit after brain injury: Clinical and theoretical perspectives (pp. 84-110). New York, NY: Oxford University Press.

McGlynn, S. M., \& Schacter, D. L. (1989). Unawareness of deficits in neuropsychological syndromes.
Journal of Clinical and Experimental Neuropsychology, 11, 143-205. http://dx.doi.org/10.1080/ 01688638908400882

Medford, N., Sierra, M., Baker, D., \& David, A. S. (2005). Understanding and treating depersonalisation disorder. Advances in Psychiatric Treatment, 11, 92-100. http://dx.doi.org/10.1192/apt.11.2.92

Midgley, M. (2014). Are you an illusion? New York, NY: Routledge.

Mograbi, D. C., Brown, R. G., \& Morris, R. G. (2009). Anosognosia in Alzheimer's disease-The petrified self. Consciousness and Cognition, 18, 989-1003. http://dx.doi.org/10.1016/j.concog .2009 .07 .005

Murphy, J. P. (1951). Frontal lobe surgery in treatment of intractable pain; a critique. The Yale Journal of Biology and Medicine, 23, 493-500.

Nadel, L., \& Moscovitch, M. (1997). Memory consolidation, retrograde amnesia and the hippocampal complex. Current Opinion in Neurobiology, 7, 217-227. http://dx.doi.org/10.1016/ S0959-4388(97)80010-4

Nadel, L., \& Peterson, M. A. (2013). The hippocampus: Part of an interactive posterior representational system spanning perceptual and memorial systems. Journal of Experimental Psychology: General, 142, 1242-1254. http://dx.doi.org/ $10.1037 / \mathrm{a} 0033690$

Nagel, T. (1974). What is it like to be a bat? The Philosophical Review, 83, 435-450. http://dx.doi .org/10.2307/2183914

Nagel, T. (2012). Mind \& cosmos: Why the materialist neo-Darwinian conception of nature is almost certainly wrong. Oxford, UK: Oxford University Press. http://dx.doi.org/10.1093/acprof:oso/ 9780199919758.001.0001

Naya, Y., \& Suzuki, W. A. (2011). Integrating what and when across the primate medial temporal lobe. Science, 333, 773-776. http://dx.doi.org/10.1126/ science. 1206773

Nelson, K. (1989). Narratives from the crib. Cambridge, MA: Harvard University Press.

Nemiah, J. C. (1962). The effect of leukotomy on pain. Psychosomatic Medicine, 24, 75-80. http:// dx.doi.org/10.1097/00006842-196201000-00012

Neuhouser, F. (1990). Fichte's theory of subjectivity. New York, NY: Cambridge University Press. http://dx.doi.org/10.1017/CBO9780511624827

Nielsen, J. M. (1938). Gerstmann syndrome: Finger agnosia, agraphia, confusion of right and left and acalculia. Archives of Neurology and Psychiatry, 39, 536-559. http://dx.doi.org/10.1001/archneur psyc. 1938.02270030114009

Nightingale, S. (1982). Somatoparaphrenia: A case report. Cortex, 18, 463-467. http://dx.doi.org/ 10.1016/S0010-9452(82)80043-9

Nisbett, R. E., \& Wilson, T. D. (1977). Telling more than we can know: Verbal reports on mental pro- 
cesses. Psychological Review, 84, 231-259. http:// dx.doi.org/10.1037/0033-295X.84.3.231

Phillips, M. L., Medford, N., Senior, C., Bullmore, E. T., Suckling, J., Brammer, M. J., . . . David, A. S. (2001). Depersonalization disorder: Thinking without feeling. Psychiatry Research, 108, 145160.

Piolino, P., Desgranges, B., Manning, L., North, P., Jokic, C., \& Eustache, F. (2007). Autobiographical memory: The sense of recollection and executive functions after severe traumatic brain injury. Cortex, 43, 176-195.

Prebble, S. C., Addis, D. R., \& Tippett, L. J. (2013). Autobiographical memory and sense of self. Psychological Bulletin, 139, 815-840. http://dx.doi .org/10.1037/a0030146

Prigatano, G. P., \& Schacter, D. L. (Eds.). (1991). Awareness of deficit after brain injury. Oxford, UK: Oxford University Press.

Pryor, J. (1999). Immunity to error through misidentification. Philosophical Topics, 26, 271-304. http://dx.doi.org/10.5840/philtopics1999261/246

Race, E., Keane, M. M., \& Verfaellie, M. (2011). Medial temporal lobe damage causes deficits in episodic memory and episodic future thinking not attributable to deficits in narrative construction. The Journal of Neuroscience, 31, 10262-10269. http://dx.doi.org/10.1523/JNEUROSCI.1145-11 .2011

Raz, M. (2009). The painless brain: Lobotomy, psychiatry, and the treatment of chronic pain and terminal illness. Perspectives in Biology and Medicine, 52, 555-565. http://dx.doi.org/10.1353/pbm .0 .0121

Rescher, N. (1984). The limits of science. Berkeley, CA: University of California Press.

Rescher, N. (1997). Objectivity: The obligations of impersonal reason. Notre Dame, IN: University of Notre Dame Press.

Reutens, S., Nielsen, O., \& Sachdev, P. (2010). Depersonalization disorder. Current Opinion in Psychiatry, 23, 278-283. http://dx.doi.org/10.1097/ YCO.0b013e3283387ab4

Robinson, D. N. (2008). Consciousness and mental life. New York, NY: Columbia University Press.

Robinson, M. F., \& Freeman, W. (1954). Psychosurgery and the self. New York, NY: Grune \& Stratton.

Rossman, N. (1991). Consciousness: Separation and integration. Albany, NY: SUNY Press.

Rubins, J. L., \& Friedman, E. D. (1948). Asymbolia for pain. Archives of Neurology and Psychiatry, 60, 554-573. http://dx.doi.org/10.1001/archneur psyc.1948.02310060007002

Russell, B. (1992). Theory of knowledge. New York, NY: Routledge. (Original work published 1913)
Russell, B. (1999). The problems of philosophy. Mineola, NY: Dover Publications. (Original work published 1912)

Schilder, P., \& Stengel, E. (1928). Schmerzasymbolie. Zeitschrift für die Gesamte Neurologie und Psychiatrie, 113, 143-158. http://dx.doi.org/ 10.1007/BF02884496

Schilder, P., \& Stengel, E. (1931). Asymbolia for pain. Archives of Neurology and Psychiatry, 25, 598-600. http://dx.doi.org/10.1001/archneurpsyc .1931 .02230030156007

Shoemaker, S. (1968). Self-reference and selfawareness. The Journal of Philosophy, 65, 555567. http://dx.doi.org/10.2307/2024121

Shoemaker, S. (1984). Identity, cause and mind. Oxford, UK: Oxford University Press.

Sierra, M., Baker, D., Medford, N., \& David, A. S. (2005). Unpacking the depersonalization syndrome: An exploratory factor analysis on the Cambridge Depersonalization Scale. Psychological Medicine, 35, 1523-1532. http://dx.doi.org/ 10.1017/S0033291705005325

Sierra, M., \& Berrios, G. E. (1997). Depersonalization: A conceptual history. History of Psychiatry, 8, 213-229. http://dx.doi.org/10.1177/ $0957154 X 9700803002$

Simeon, D. (2004). Depersonalisation disorder. CNS Drugs, 18, 343-354. http://dx.doi.org/10.2165/ 00023210-200418060-00002

Simeon, D., \& Abugel, J. (2006). Feeling unreal: Depersonalisation disorder and the loss of the self. Oxford, UK: Oxford University Press.

Squire, L. R. (2004). Memory systems of the brain: A brief history and current perspective. Neurobiology of Learning and Memory, 82, 171-177. http:// dx.doi.org/10.1016/j.nlm.2004.06.005

Stephens, G. L., \& Graham, G. (2000). When selfconsciousness breaks: Alien voices and inserted thoughts. Cambridge, MA: The MIT Press.

Strawson, G. (2009a). Mental Reality (2nd ed.). Cambridge, MA: MIT Press. http://dx.doi.org/10.7551/ mitpress/9780262513104.001.0001

Strawson, G. (2009b). Selves: An essay in revisionary metaphysics. New York, NY: Oxford University Press. http://dx.doi.org/10.1093/acprof:oso/ 9780198250067.001.0001

Talland, G. A. (1964). Self-reference: A neglected component in remembering. American Psychologist, 19, 351-353. http://dx.doi.org/10.1037/ h0039768

Textor, M. (2013). Brentano on the dual relation of the mental. Phenomenology and the Cognitive Sciences, 12, 465-483. http://dx.doi.org/10.1007/ s11097-012-9281-z

Tulving, E. (1983). Elements of episodic memory. New York, NY: Oxford University Press. 
Tulving, E. (1985). Memory and consciousness. Canadian Psychology/Psychologie canadienne, 26, 1-12. http://dx.doi.org/10.1037/h0080017

Tulving, E. (2005). Episodic memory and autonoesis: Uniquely human? In H. S. Terrace \& J. Metcalfe (Eds.), The missing link in cognition: Origins of self-reflective consciousness (pp. 3-56). Oxford, UK: Oxford University Press. http://dx.doi.org/ 10.1093/acprof:oso/9780195161564.003.0001

Tulving, E., \& Szpunar, K. K. (2012). Does the future exist? In B. Levine \& F. I. M. Craik (Eds.), Mind and the frontal lobes: Cognition, behavior, and brain imaging (pp. 248-263). New York, NY: Oxford University Press.

Vallar, G., \& Ronchi, R. (2009). Somatoparaphrenia: A body delusion. A review of the neuropsychological literature. Experimental Brain Research, 192, 533-551. http://dx.doi.org/10.1007/s00221-0081562-y

Varela, F. J., Thompson, E., \& Rosch, E. (1993). The embodied mind: Cognitive science and human experience. Cambridge, MA: The MIT Press.

Wallace, R. A. (2003). Choosing reality: A Buddhist view of physics and the mind. Ithaca, NY: Snow Lion Publications.

Weber, M., \& Weekes, A. (2009). Process approaches to consciousness in psychology, neuroscience, and philosophy of mind. Albany, NY: SUNY Press.

Weiskrantz, L. (1997). Consciousness lost and found: A neuropsychological exploration. Oxford, UK: Oxford University Press.
Wheeler, M. A., Stuss, D. T., \& Tulving, E. (1997). Toward a theory of episodic memory: The frontal lobes and autonoetic consciousness. Psychological Bulletin, 121, 331-354. http://dx.doi.org/10.1037/ 0033-2909.121.3.331

Wittgenstein, L. (1958). The blue and brown books (Rush Rees, Ed.). New York, NY: Harper and Row.

Zahavi, D. (2005). Subjectivity of selfhood: Investigating the first-person Perspective. Cambridge, MA: The MIT Press.

Zahavi, D. (2011). The experiential self: Objections and clarifications. In M. Siderits, E. Thompson, \& D. Zahavi (Eds.), Self, no self: Perspectives from analytical phenomenological and Indian traditions (pp. 56-78). Oxford, UK: Oxford University Press.

Zahn, R., Talazko, J., \& Ebert, D. (2008). Loss of the sense of self-ownership for perceptions of objects in a case of right inferior temporal, parietooccipital and precentral hypometabolism. Psychopathology, 41, 397-402. http://dx.doi.org/10.1159/ 000158228

Zemach, E. M. (1983). Memory: What it is, and what it cannot possibly be. Philosophy \& Phenomenological Research, 44, 31-44. http://dx.doi.org/ $10.2307 / 2107578$

Received February 8, 2015 Revision received March 23, 2015 Accepted March 29, 2015 